\title{
Homocysteine as a risk factor for CVD mortality in men with other CVD risk factors: the Kuopio Ischaemic Heart Disease Risk Factor (KIHD) Study
}

\author{
J. K. VIRTANEN ${ }^{1}$, S. VOUTILAINEN ${ }^{1}$, G. ALFTHAN ${ }^{2}$, M. J. KORHONEN ${ }^{3}$, \\ T. H. RISSANEN ${ }^{1,3}$, J. MURSU ${ }^{1}$, G. A. KAPLAN ${ }^{4} \& J \cdot T \cdot \operatorname{SALONEN}^{1,5}$ \\ From the ${ }^{1}$ Research Institute of Public Health, University of Kuopio, Kuopio, ${ }^{2}$ Biomarker Laboratory, National Public Health Institute, Helsinki, \\ ${ }^{3}$ Department of Public Health and General Practice, University of Kuopio, Kuopio, Finland, ${ }^{4}$ Department of Epidemiology, School of Public Health, \\ University of Michigan, Ann Arbor, MI, USA, and ${ }^{5} \mathrm{Oy}$ Jurilab Ltd, Kuopio, Finland
}

\begin{abstract}
Virtanen JK, Voutilainen S, Alfthan G, Korhonen MJ, Rissanen TH, Mursu J, Kaplan GA, Salonen JT (University of Kuopio, Kuopio; National Public Health Institute, Helsinki, Finland; University of Michigan, Ann Arbor, USA; and Oy Jurilab Ltd, Kuopio, Finland). Homocysteine as a risk factor for CVD mortality in men with other CVD risk factors: the Kuopio Ischaemic Heart Disease Risk Factor (KIHD) Study. J Intern Med 2005; 257: 255-262.
\end{abstract}

Objective. Based on case-control and prospective studies elevated blood total homocysteine (tHcy) has been suggested to be an independent risk factor for cardiovascular diseases (CVD). The purpose of the study was to explore the joint effect of increased serum tHcy concentration and other risk factors on the risk of CVD mortality in middle-aged men without a history of heart disease or stroke.

Design. A prospective, population-based Kuopio Ischaemic Heart Disease Risk Factor (KIHD) Study. Setting. Eastern Finland.
Subjects. A total of 802 men aged 46-64 years, examined in 1991-93.

Main outcome measures. CVD mortality event.

Results. The mean serum tHcy concentration was $10.8 \mu \mathrm{mol} \mathrm{L}{ }^{-1}$ (SD 3.3). During the average followup time of 10.8 years 50 men experienced a CVD death. The hazard rate ratio for CVD mortality was 1.80 (95\% confidence interval: $1.02-3.19)$ in men in the highest serum tHcy third versus lower thirds after adjustment for cardiovascular risk factors. Furthermore, elevated serum tHcy concentration appeared to increase the risk of CVD death in men who smoke or who have high circulating concentrations of serum total or LDL cholesterol, apo-B apolipoprotein or plasma fibrinogen.

Conclusion. We conclude that homocysteine may increase the risk of CVD mortality in middle-aged men from Eastern Finland, and it may especially increase the risk when present with other risk factors for CVD.

Keywords: cardiovascular disease, homocysteine, interaction, prospective studies, risk factors.

\section{Introduction}

Elevated blood levels of total homocysteine (tHcy), a nonprotein-forming sulphur amino acid, have been suggested to be an independent risk factor for cardiovascular disease (CVD) [1]. Homocysteine is derived from the metabolic demethylation of dietary methionine. It can be either remethylated back to methionine in a reaction which is catalysed by methionine synthase with folate as the methyl donor and vitamin $\mathrm{B}_{12}$ (cobalamin) as a cofactor or it can be catabolized to cystathionine in a trans-sulfuration pathway catalysed by cystathionine beta-synthase. In this latter pathway vitamin $\mathrm{B}_{6}$ (pyridoxine) is an essential cofactor.

Not all prospective studies have shown an association between plasma/serum tHcy and risk of heart disease. For example, in the Finnish prospective studies looking at the effects of tHcy on the risk of heart disease, elevated plasma tHcy concentrations 
have not been shown to increase the risk of CVD in middle-aged men and women free of prior coronary event [2-4]. However, the data on the effects of increased blood tHcy concentrations on mortality risk in subpopulations with CVD risk factors is scarce. Hyperhomocysteinemia has been suggested to contribute to the atherosclerotic processes in similar ways as hypercholesterolaemia and high plasma fibrinogen $[1,5,6]$. Therefore it can be speculated that in subjects with these risk factors, elevated blood tHcy may further increase the risk of CVD. Furthermore, there is some previous data that tHcy may be an independent risk factor in subjects with increased serum total or LDL cholesterol or plasma fibrinogen concentrations or who smoke [7-11]. Thus, we wanted to test the hypothesis that tHcy contributes to the risk of CVD death in middleaged men with increased serum total or LDL cholesterol or plasma fibrinogen concentrations or in men who smoke. The combined effect of tHcy and serum apo-B was also investigated, as apo-B is one of the lipoproteins of LDL and it has been found to be a risk factor for CVD [12].

\section{Materials and methods}

\section{Study population}

The Kuopio Ischaemic Heart Disease Risk Factor Study (KIHD) is an ongoing prospective populationbased cohort study designed to investigate risk factors for CVD, atherosclerosis and related outcomes in middle-aged men from eastern Finland [13], the population with one of the highest recorded rates of coronary heart disease (CHD). A total of 2682 participants ( $82.9 \%$ of eligible), aged 42,48 , 54 , or 60 years, were enrolled in the study between 1984 and 1989. The study protocol was approved by the Research Ethics Committee of the University of Kuopio. All subjects gave their written informed consent for participation. The baseline examinations for the present analysis were carried out during 1991-93 at the 4-year re-examinations of the KIHD study. Of the total of 1229 men eligible for the study, 52 had died, had had a severe illness, or had migrated from the region, and 139 could not be contacted or refused to participate. Thus, 1038 men were examined in 1991-93. Men with a prevalent CHD or stroke $(n=225)$ were excluded from the present analyses. Of the remaining 813 men, data on serum tHcy concentrations were available for 802 men.

\section{Determination of serum tHcy concentration}

The subjects came to give venous blood samples between $8 \mathrm{Am}$ and $10 \mathrm{AM}$. They were instructed to abstain from ingesting alcohol for 3 days and from smoking and eating for $12 \mathrm{~h}$ prior to giving the sample.

The serum tHcy concentration was analysed by high-performance liquid chromatography in 2001 at the National Public Health Institute, Helsinki, Finland, as described by Schwab et al. [14]. The results represent total serum homocysteine, which is referred as serum tHcy. The coefficient of variation between batches $(n=30)$ for two pooled serum samples were $4.3 \%$ and $5.4 \%$.

\section{Other measurements}

Assessment of medical history, smoking, alcohol consumption and blood pressure was carried out as described previously [15]. The collection of blood specimens [15] and measurement of serum lipids and lipoproteins [16] and plasma fibrinogen [17] have been described in detail elsewhere. Body mass index was computed as the ratio of weight in kilograms to the square of height in metres.

\section{Ascertainment of follow-up events}

The CVD deaths were ascertained by a computer linkage to the national death registry using the Finnish personal identification code (social security number). All CVD deaths that occurred from the study entry to 31 December 2003 were included. There were no losses to follow-up. CVD deaths were coded according to the ICD-9 (International Classification of Diseases, Ninth Revision, code numbers 390-459) or the ICD-10 (code numbers I00-I99).

\section{Statistical analysis}

The data are expressed as mean \pm SD. Mean values were compared by analysis of variance (ANOVA). Correlations between serum tHcy and risk factors studied were estimated with Pearson correlation coefficients $(r)$. The relationship of serum tHcy with the risk of CVD mortality was analysed using Cox 
proportional hazards models. Risk factor-adjusted hazard rate ratios (RR) were estimated as the antilogarithms of coefficients from multivariable models. Due to a limited number of cases only a few covariates could be used without over-fitting the models. The inclusion of covariates was based on a change in RR of at least $10 \%$. When this criterion was used, smoking, systolic blood pressure and serum LDL cholesterol in addition to age and examination years remained in the models examining the effects of tHcy on the risk of CVD mortality in the whole population. Only systolic blood pressure remained as a covariate in addition to the age and examination years in the models examining the effects of tHcy with other risk factor. Interactions of homocysteine with fibrinogen, total and LDL cholesterol, apo-B and smoking were assessed by stratified analyses and the use of a product term with both risk factors as binary variables. Serum tHcy level was categorized as low to moderate and high according to the highest tertile $\left(>11.3 \mu \mathrm{mol} \mathrm{L}^{-1}\right)$. Plasma fibrinogen, serum total and LDL cholesterol and apo-B were categorized as high or low according to the median value. Smoking was categorized as yes/no. A subject was defined as a smoker if he had ever smoked on a regular basis and had smoked cigarettes, cigars, or a pipe within the past 30 days. For the evaluation of joint effect, four categories were generated: (i) neither risk factor present, (ii) increased serum level of tHcy alone, (iii) other risk factor alone, and (iv) increased serum level of tHcy and other risk factor present. The confidence intervals (CI) were estimated on the basis of the assumption of asymptotic normality of the estimates. All tests of significance were two-sided. Pvalues $<0.05$ were considered statistically significant except in interaction analyses where $P$-values $<0.20$ were considered significant. Data were analysed using sPSS 11.0 for Windows (SPSS Inc., Chicago, IL, USA).

\section{Results}

The mean serum tHcy concentration was $10.8 \mu \mathrm{mol} \mathrm{L}^{-1}$ (SD 3.3), median was $10.3 \mu \mathrm{mol} \mathrm{L}{ }^{-1}$. The subjects were divided into thirds based on the serum tHcy concentrations. Table 1 presents selected characteristics of the subjects in the highest serum tHcy third, in the two lower thirds and in the whole study population. The men in the highest third $\left(>11.3 \mu \mathrm{mol} \mathrm{L}^{-1}\right.$ ) were significantly older, had lower serum total cholesterol concentration and higher systolic blood pressure and smoked less than men in the lower thirds.

During an average follow-up time of 10.8 years ( $\sim 8700$ person-years of follow-up) 50 men free of CHD and stroke at baseline experienced a CVD death. The RR for CVD mortality was 1.72 (95\% CI:
Table 1 Characteristics of the study population at baseline

\begin{tabular}{|c|c|c|c|c|}
\hline & \multicolumn{3}{|c|}{$\begin{array}{l}\text { Serum total homocysteine concentration } \\
\left(\mu \mathrm{mol} \mathrm{L} \mathrm{L}^{-1}\right)\end{array}$} & \multirow[b]{2}{*}{$P^{*}$} \\
\hline & $\leq 9.5$ & $9.5-11.3$ & $>11.3$ & \\
\hline No. of subjects & 267 & 269 & 266 & \\
\hline Serum tHcy $\left(\mu \mathrm{mol} \mathrm{L}{ }^{-1}\right)$ & $8.3(0.9)$ & $10.4(0.5)$ & $13.7(4.2)$ & $<0.001$ \\
\hline Age (years) & $54.2(6.4)$ & $55.3(6.6)$ & $56.4(6.6)$ & $<0.001$ \\
\hline Serum total cholesterol $\left(\mathrm{mmol} \mathrm{L}^{-1}\right)$ & $5.50(0.92)$ & $5.64(0.90)$ & $5.41(0.88)$ & 0.041 \\
\hline Serum LDL cholesterol $\left(\mathrm{mmol} \mathrm{L}^{-1}\right)$ & $3.89(0.82)$ & $4.04(0.82)$ & $3.84(0.78)$ & 0.108 \\
\hline Serum HDL cholesterol $\left(\mathrm{mmol} \mathrm{L}^{-1}\right)$ & $1.13(0.29)$ & $1.13(0.27)$ & $1.10(0.30)$ & 0.081 \\
\hline Serum triglycerides $\left(\mathrm{mmol} \mathrm{L}^{-1}\right)$ & $1.55(0.96)$ & $1.55(1.15)$ & $1.61(0.99)$ & 0.548 \\
\hline Systolic blood pressure (mmHg) & $134(17)$ & $135(16)$ & $137(17)$ & 0.029 \\
\hline Body mass index $\left(\mathrm{kg} \mathrm{m}^{-2}\right)$ & $27.3(3.6)$ & $27.5(3.5)$ & $27.5(3.5)$ & 0.725 \\
\hline Alcohol intake (g week ${ }^{-1}$ ) & $81.2(108.8)$ & $72.6(93.2)$ & $82.7(120.6)$ & 0.528 \\
\hline Serum apo-B $\left(\mathrm{g} \mathrm{L}^{-1}\right)$ & $0.96(0.26)$ & $0.97(0.23)$ & $0.95(0.24)$ & 0.506 \\
\hline Plasma fibrinogen $\left(\mathrm{g} \mathrm{L}^{-1}\right)$ & $3.13(0.59)$ & $3.12(0.54)$ & $3.11(0.57)$ & 0.662 \\
\hline Current smoker (\%) & 31.1 & 26.8 & 22.6 & 0.041 \\
\hline Diabetes (\%) & 5.2 & 7.8 & 4.9 & 0.329 \\
\hline $\begin{array}{l}\text { Family history of ischaemic } \\
\text { heart disease }(\%)\end{array}$ & 50.6 & 51.7 & 48.9 & 0.501 \\
\hline
\end{tabular}

Values are given as mean (SD) or proportions.

${ }^{*} P$ for highest vs. lower two-thirds 
Table 2 The age-, examination year- and systolic blood pressureadjusted hazard rate ratios (RR) in the highest tHcy third $\left(>11.3 \mu \mathrm{mol} \mathrm{L}^{-1}\right)$ compared with the lower thirds in the risk factor groups

\begin{tabular}{|c|c|c|c|}
\hline & RR (95\% CI) & $\begin{array}{l}P \text { for } \\
\text { trend }\end{array}$ & $\begin{array}{l}\text { No. of cases } \\
\text { (\% in group) }\end{array}$ \\
\hline \multicolumn{4}{|l|}{ Plasma fibrinogen } \\
\hline$\leq 3.0 \mathrm{~g} \mathrm{~L}^{-1}$ & $0.87(0.32-2.34)$ & 0.769 & $18(4.3)$ \\
\hline$>3.0 \mathrm{~g} \mathrm{~L}^{-1}$ & $2.25(1.10-4.59)$ & 0.052 & $32(8.3)$ \\
\hline \multicolumn{4}{|c|}{ Serum total cholesterol } \\
\hline$\leq 5.5 \mathrm{mmol} \mathrm{L}^{-1}$ & $1.49(0.61-3.65)$ & 0.600 & $20(5.0)$ \\
\hline$>5.5 \mathrm{mmol} \mathrm{L}^{-1}$ & $1.93(0.93-3.97)$ & 0.139 & $30(7.4)$ \\
\hline \multicolumn{4}{|c|}{ Serum LDL cholesterol } \\
\hline$\leq 3.9 \mathrm{mmol} \mathrm{L}^{-1}$ & $1.05(0.43-2.56)$ & 0.737 & $21(5.3)$ \\
\hline$>3.9 \mathrm{mmol} \mathrm{L}^{-1}$ & $2.21(1.05-4.62)$ & 0.043 & $29(7.2)$ \\
\hline \multicolumn{4}{|l|}{ Serum Apo-B } \\
\hline$\leq 0.93 \mathrm{~g} \mathrm{~L}^{-1}$ & $1.47(0.57-3.75)$ & 0.443 & $18(4.4)$ \\
\hline$>0.93 \mathrm{~g} \mathrm{~L}^{-1}$ & $1.91(0.94-3.86)$ & 0.211 & $32(8.1)$ \\
\hline \multicolumn{4}{|l|}{ Smoker } \\
\hline No & $1.35(0.66-2.76)$ & 0.987 & $31(5.3)$ \\
\hline Yes & $2.80(1.12-6.99)$ & 0.009 & $19(8.8)$ \\
\hline
\end{tabular}

0.98-3.01, $P$ for trend 0.113) in men in the highest homocysteine third versus lower thirds after adjusting for age and examination year in the whole population. After additional adjustments for smoking, serum LDL cholesterol and systolic blood pressure the RR was 1.80 (95\% CI: $1.02-3.19, P$ for trend 0.097).

The effect of increased serum tHcy concentration on CVD mortality risk was then studied separately in men with and without other risk factor present (Table 2). Increased serum tHcy (>11.3 $\mu \mathrm{mol} \mathrm{L}^{-1}$ ) was associated with an age-, examination year- and systolic blood pressure-adjusted RR for CVD mortality of 2.25 (95\% CI: 1.10-4.59) in men with increased plasma fibrinogen, 1.93 (95\% CI: 0.933.97) increased serum total cholesterol, 2.21 (95\% CI: 1.05-4.62) increased serum LDL cholesterol, 1.91 (95\% CI: 0.94-3.86) increased serum apo-B, and 2.80 (95\% CI: 1.12-6.99) amongst smokers. No

Table 3 Hazard rate ratios (RR) for CVD mortality models

\begin{tabular}{|c|c|c|c|c|c|c|c|}
\hline \multirow[b]{2}{*}{ Group } & \multirow{2}{*}{$\begin{array}{l}\text { tHcy } \\
\left.(\mu \mathrm{mol} \mathrm{L})^{-1}\right)\end{array}$} & & \multicolumn{2}{|c|}{$\begin{array}{l}\text { Age and examination } \\
\text { year-adjusted models }\end{array}$} & \multicolumn{2}{|c|}{$\begin{array}{l}\text { Age, examination year and } \\
\text { systolic blood pressure-adjusted } \\
\text { models }\end{array}$} & \multirow{2}{*}{$\begin{array}{l}\text { No. of cases } \\
\text { (\% in group }\end{array}$} \\
\hline & & & $\mathrm{RR}(95 \% \mathrm{CI})$ & $P$ & $\operatorname{RR}(95 \% \mathrm{CI})$ & $P$ & \\
\hline & & Fib $\left(\mathrm{g} \mathrm{L}^{-1}\right)$ & & & & & \\
\hline 1 & $\leq 11.3$ & $\leq 3.0$ & 1 & & 1 & & $12(4.3)$ \\
\hline 2 & $\leq 11.3$ & $>3.0$ & $1.20(0.55-2.62)$ & 0.647 & $1.13(0.52-2.47)$ & 0.766 & $14(5.4)$ \\
\hline 3 & $>11.3$ & $\leq 3.0$ & $0.92(0.34-2.47)$ & 0.870 & $0.95(0.35-2.53)$ & 0.814 & $6(4.3)$ \\
\hline 4 & $>11.3$ & $\begin{array}{l}>3.0 \\
\text { Chol }\left(\mathrm{mmol} \mathrm{L}^{-1}\right)\end{array}$ & $2.96(1.39-6.29)$ & 0.005 & $2.48(1.16-5.34)$ & 0.020 & $18(13.8)$ \\
\hline 1 & $\leq 11.3$ & $\leq 5.5$ & 1 & & 1 & & $10(3.9)$ \\
\hline 2 & $\leq 11.3$ & $>5.5$ & $1.51(0.68-3.32)$ & 0.310 & $1.52(0.69-3.34)$ & 0.302 & $16(5.7)$ \\
\hline 3 & $>11.3$ & $\leq 5.5$ & $1.58(0.65-3.81)$ & 0.311 & $1.45(0.60-3.51)$ & 0.409 & $10(6.9)$ \\
\hline 4 & $>11.3$ & $\begin{array}{l}>5.5 \\
\mathrm{LDL}\left(\mathrm{mmol} \mathrm{L}^{-1}\right)\end{array}$ & $2.95(1.30-6.68)$ & 0.009 & $2.94(1.30-6.65)$ & 0.010 & $11(11.3)$ \\
\hline 1 & $\leq 11.3$ & $\leq 3.9$ & 1 & & 1 & & $12(4.6)$ \\
\hline 2 & $\leq 11.3$ & $>3.9$ & $1.08(0.50-2.34)$ & 0.842 & $1.01(0.46-2.19)$ & 0.986 & $14(5.1)$ \\
\hline 3 & $>11.3$ & $\leq 3.9$ & $1.27(0.53-3.02)$ & 0.594 & $1.10(0.46-2.65)$ & 0.829 & $9(6.5)$ \\
\hline 4 & $>11.3$ & $\begin{array}{l}>3.9 \\
\text { Apo-B }\left(\mathrm{mg} \mathrm{dL}^{-1}\right)\end{array}$ & $2.41(1.11-5.21)$ & 0.026 & $2.33(1.08-5.05)$ & 0.032 & $15(11.5)$ \\
\hline 1 & $\leq 11.3$ & $\leq 0.93$ & 1 & & 1 & & $9(3.4)$ \\
\hline 2 & $\leq 11.3$ & $>0.93$ & $1.98(0.88-4.44)$ & 0.099 & $1.77(0.79-3.98)$ & 0.169 & $17(6.4)$ \\
\hline 3 & $>11.3$ & $\leq 0.93$ & $1.71(0.68-4.33)$ & 0.255 & $1.53(0.60-3.89)$ & 0.710 & $9(6.3)$ \\
\hline 4 & $>11.3$ & $\begin{array}{l}>0.93 \\
\text { Smoker }\end{array}$ & $3.58(1.57-8.26)$ & 0.003 & $3.25(1.41-7.50)$ & 0.006 & $15(11.8)$ \\
\hline 1 & $\leq 11.3$ & No & 1 & & 1 & & $17(4.5)$ \\
\hline 2 & $\leq 11.3$ & Yes & $1.47(0.65-3.32)$ & 0.352 & $1.58(0.70-3.58)$ & 0.276 & $9(5.8)$ \\
\hline 3 & $>11.3$ & No & $1.35(0.66-2.75)$ & 0.412 & $1.28(0.63-2.61)$ & 0.499 & $14(6.7)$ \\
\hline 4 & $>11.3$ & Yes & $4.53(2.06-9.95)$ & $<0.001$ & $4.69(2.13-10.33)$ & $<0.001$ & $10(16.7)$ \\
\hline
\end{tabular}

Hazard rate ratios with $95 \%$ confidence intervals and $P$ values are presented using patients with neither high tHcy nor other risk factor (group 1) as the reference group.

Fib, plasma fibrinogen; Chol, serum total cholesterol. 

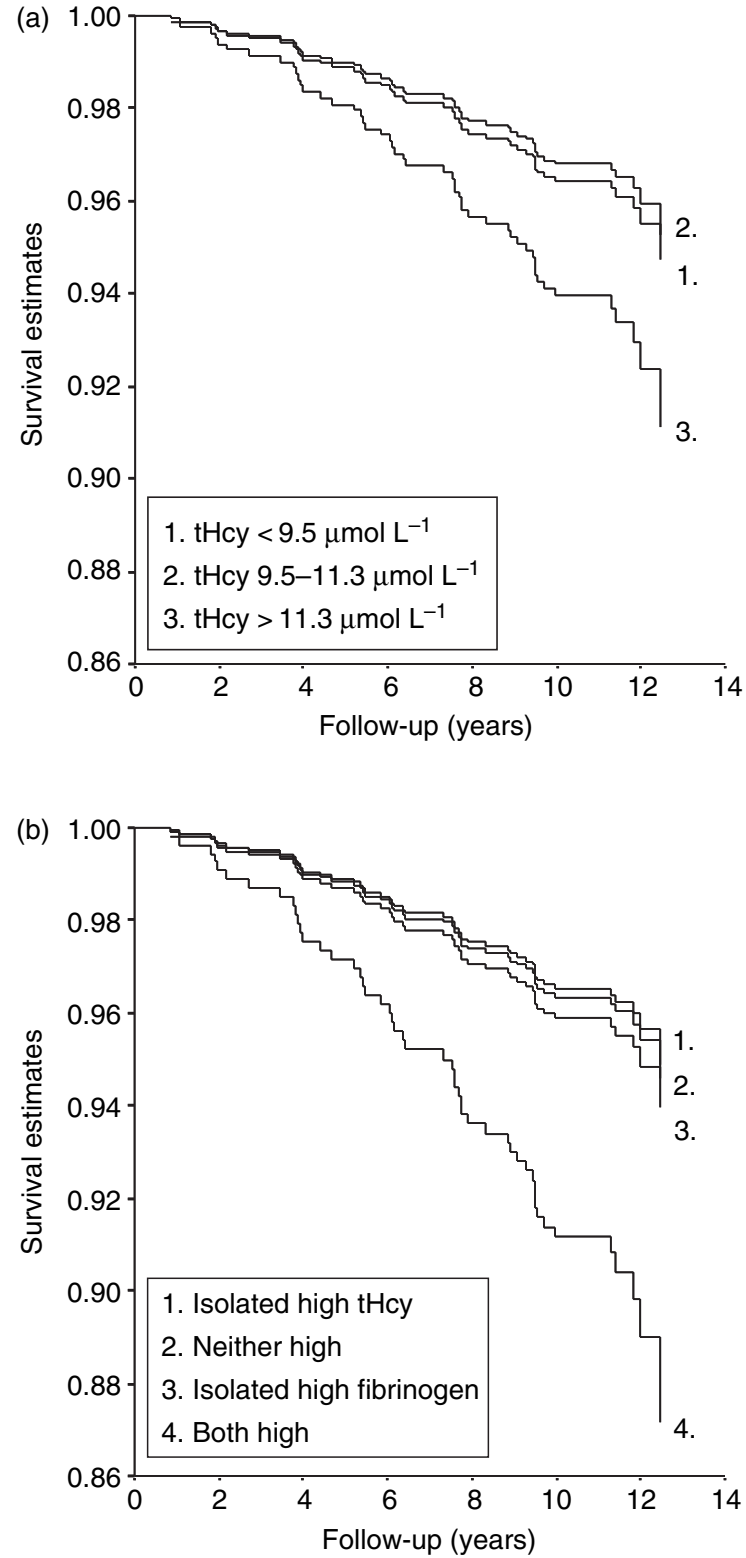

Fig. 1 Age, examination year, smoking, serum LDL cholesterol and systolic blood pressure-adjusted survival curves for total homocysteine (tHcy) alone (a) and age-, examination yearand systolic blood pressure-adjusted survival curves for tHcyfibrinogen by group (b).

association between elevated serum tHcy and CVD mortality was observed amongst men without these risk factors (Table 2). The age-, examination yearand systolic blood pressure-adjusted $P$ value for the interaction between tHcy and fibrinogen was 0.163 , between tHcy and total cholesterol 0.619, between tHcy and LDL cholesterol 0.201, between tHcy and apo-B 0.759 and between tHcy and smoking 0.149 .

In Table 3 are presented the RRs for subjects with both risk factors (increased serum tHcy and either increased serum total or LDL cholesterol or apo-B, plasma fibrinogen, or smoking), isolated risk factor or neither risk factor. The age- and examination year-adjusted risk of CVD death was significantly increased in subjects with both increased serum tHcy and either increased plasma fibrinogen, serum total cholesterol, serum apo-B or who were smokers compared with subjects with neither risk factor. Additional adjustment for systolic blood pressure only slightly attenuated the associations, except in smokers where the risk was slightly increased. Figure 1 presents the age-, examination year- and systolic blood pressure-adjusted survival curves for tHcy in the whole population (Fig. 1a) and for the homocysteine-fibrinogen group (Fig. 1b).

\section{Discussion}

The results of this study suggest that high serum tHcy concentration may increase the risk of CVD mortality in middle-aged men from Eastern Finland and especially in men with other prevalent CVD risk factors, i.e. who are smokers or having high circulating concentrations of serum total or LDL cholesterol, apo-B apolipoprotein or plasma fibrinogen. There are a few limitations in our study. First, the follow-up period was relatively short, so we had a limited number of outcome events, reducing the power of the study. We cannot exclude the possibility that the result that high serum tHcy concentration is a risk factor for CVD mortality in men with other heart disease risk factors was confounded by other factors associated with increased risk of CVD death. Due to the small number of events, it was not possible to include multiple covariates in the models.

Secondly, the long storage time of the serum samples at $-20{ }^{\circ} \mathrm{C}$, which could potentially weaken the reliability of serum determinations. However, it has been shown that long storage time of serum homocysteine samples does not apparently lead to alterations in homocysteine concentrations [3]. In addition, all serum samples underwent the same freeze-thaw history and were analysed within a short period of time. The analytical variation in our study was also very low. 
The finding of this study that elevated serum tHcy is a risk factor for CVD mortality is compatible with some of the previous cohort studies, which have studied the risk of CVD death in both men and women [18-20].

However, the main finding in this study was that increased serum tHcy levels appeared to increase the risk of CVD mortality in subjects with other CVD risk factors, although the interaction between tHcy and other risk factor was considered statistically significant only in case of high serum tHcy with high plasma fibrinogen $(P$ value for the interaction term $=0.163)$ or high serum tHcy and smoking $(P=0.149)$ [21]. The $P$ value for the interaction term between tHcy and serum LDL did not quite reach significance $(P=0.201)$.

Hypercholesterolaemia [22], increased fibrinogen [9, 23], and apo-B lipoprotein [12] concentrations, and smoking [24] are all well-known risk factors for CVD mortality. There are previous studies where increased tHcy concentration has been observed to be an independent risk factor for coronary artery disease when other risk factors pre-exist. In one study carried out in hypercholesterolaemic subjects the risk of an atherosclerotic event in the highest plasma tHcy fifth was 2.8 times higher when compared with the lowest fifth [7]. In addition, $72 \%$ of the hypercholesterolaemic subjects with high plasma tHcy concentrations had sustained an atherosclerotic vascular event, whilst in the hypercholesterolaemic group without increased tHcy concentrations the occurrence was only 44\% [7]. Another study carried out in subjects with elevated LDL cholesterol concentrations found that even mildly increased plasma tHcy levels were of crucial importance for deterioration of endothelial function [8]. Hypercholesterolaemia has been shown to impair stimulated endothelium-dependent vasodilatation and there is also some evidence that hyperhomocysteinemia is associated with arterial endothelial dysfunction [5, 25, 26]. Increased risk of mortality in the subjects with both elevated cholesterol and tHcy concentrations may be explained by deterioration of endothelial function, which has been recently demonstrated [27]. The fact that apo-B is a protein component of LDL may give an explanation to the observation that homocysteine is also a risk factor for CVD mortality in men with elevated plasma apo-B concentrations.
Similar findings to those found in hypercholesterolaemic patients have also been reported in case of increased plasma fibrinogen levels. Acevedo et al. [9] reported that although no significant interaction was demonstrated between fibrinogen and homocysteine, increased plasma tHcy provided an additive contribution to the risk of elevated fibrinogen concentrations. Compared with the subjects who had neither high fibrinogen nor tHcy concentrations, patients with increased fibrinogen had a 2.3 times and subjects with both increased fibrinogen and tHcy a 3.3 times the risk of coronary artery disease mortality. The difference in this study compared with our study is that it included both men and women, and also patients with prevalent coronary artery disease $(56 \%$ of study population); $76 \%$ of the cases had a known coronary artery disease. The follow-up time was also shorter $(30 \pm 14$ months). The high risk observed in this study may partly be a result of the inclusion of subjects with prevalent CHD or due to relatively short follow-up time. However, the increased risk with increased fibrinogen and tHcy concentrations could be explained by their complementary roles in the platelet activationaggregation cascade. Fibrinogen represents a major step in platelet aggregation, whilst homocysteine impairs nitric oxide production and also contributes to the generation of oxidized species $[1,6,28]$.

The observation that elevated serum tHcy concentration appeared to increase the risk of CVD mortality in smoking men is similar to a recent European Concerted Action Project case-control study, where smokers were at increased risk of vascular disease and the risk was greatly increased in the presence of a raised plasma tHcy concentration when compared with nonsmokers [10]. In previous studies cigarette smoking has been shown to be associated with increased plasma tHcy levels $[10,11]$, but in our study population this is not seen.

Although the mean serum tHcy concentrations have been similar to the other studies in the Finnish studies [2-4], severe or moderate hyperhomocysteinemia is relatively uncommon in Finland. In our study only 11 subjects (1.4\%) had serum tHcy values more than $20 \mu \mathrm{mol} \mathrm{L}{ }^{-1}$. The null findings in another Finnish study were suggested to be due to low prevalence of mutations predisposing to 
hyperhomocysteinemia in the Finnish population [3]. Indeed, homocystinuria is one of the hereditary disorders that are rare in Finland [29]. Furthermore, in our study population the prevalence of homozygotes for the methylenetetrahydrofolate reductase (MTHFR) C677T mutation was found to be $5.3 \%$, if men with prior CHD were not excluded from the analyses (S. Voutilainen and J.K. Virtanen, unpublished data). This is somewhat lower than what has been reported in other studies (10-48\%) [30, 31].

An alternative explanation for the findings of this study could be that homocysteine is just a marker for CVD. This would be a likely option, especially if the ongoing folic acid supplementation trials fail to show any beneficial effect on the risk of CVD despite decreased blood tHcy levels. If this is the case, then the increased risk observed when high blood tHcy concentration is present with other CVD risk factors could represent an overall deterioration of vascular health.

In conclusion, high serum tHcy may increase the risk of CVD mortality in middle-aged men from Eastern Finland, and it may especially increase the risk when present with other CVD risk factors, although in this study the number of CVD deaths is too low to draw any definite conclusions. If the results of this study can be confirmed in other prospective cohort studies, then treatment for increased homocysteine concentrations should also be considered in addition to treatments for the other risk factors in the high-risk populations.

\section{Conflict of interest statement}

No conflict of interest was declared.

\section{Acknowledgements}

We thank biochemists Dr Kristiina Nyyssönen and Dr Jari Kaikkonen (http://www.Jurilab.com) for supervising the biochemical measurements and our staff for helping with data collection. This work was supported by grants from the Academy of Finland (grants 41471, 1041086 and 2041022 for J.T. Salonen and grants 201688 and 80185 for S. Voutilainen), Yrjö Jahnsson Foundation, Juho Vainio Foundation, the Finnish Cultural Foundation and the Finnish Foundation for Cardiovascular Research (to J.K. Virtanen).

\section{References}

1 Mangoni AA, Jackson SHD. Homocysteine and cardiovascular disease: current evidence and future prospects. Am J Med 2002; 112: 556-65.

2 Voutilainen S, Lakka TA, Hämelahti P, Lehtimäki T, Poulsen HE, Salonen JT. Plasma total homocysteine concentration and the risk of acute coronary events: the Kuopio Ischaemic Heart Disease Risk Factor Study. J Intern Med 2000; 248: 217-22.

3 Alfthan G, Pekkanen J, Jauhiainen M et al. Relation of serum homocysteine and lipoprotein(a) concentrations to atherosclerotic disease in a prospective Finnish population based study. Atherosclerosis 1994; 106: 9-19.

4 Knekt P, Reunanen A, Alfthan G et al. Hyperhomocystinemia. A risk factor or a consequence of coronary heart disease? Arch Intern Med 2001; 161: 1589-94.

5 Woo KS, Chook P, Lolin Y et al. Hyperhomocysteinemia is a risk factor for arterial endothelial dysfunction in humans. Circulation 1997; 96: 2542-4.

6 Welch GN, Loscalzo J. Homocysteine and atherothrombosis. N Engl J Med 1998; 338: 1042-50.

7 Glueck CJ, Shaw P, Land JE, Tracy T, Sieve-Smith L, Wang Y. Evidence that homocysteine is an independent risk factor for atherosclerosis in hyperlipidemic patients. Am J Cardiol 1995; 75: 132-6.

8 Schlaich MP, John S, Jacobi J, Lackner KJ, Schmieder RE. Mildly elevated homocysteine concentrations impair endothelium dependent vasodilation in hypercholesterolemic patients. Atherosclerosis 2000; 153: 383-9.

9 Acevedo M, Pearce GL, Kottke-Marchant K, Sprecher DL. Elevated fibrinogen and homocysteine levels enhance the risk of mortality in patients from a high-risk preventive cardiology clinic. Arterioscler Thromb Vasc Biol 2002; 22: 1042-5.

10 O'Callaghan P, Meleady R, Fitzgerald T, Graham I, the European COMAC group. Smoking and plasma homocysteine. Eur Heart J 2002; 23: 1580-6.

11 Nygard O, Refsum H, Ueland PM, Vollset SE. Major lifestyle determinants of plasma total homocysteine distribution: The Hordaland Homocysteine Study. Am J Clin Nutr 1998; 67: 263-70.

12 Walldius G, Jungner I, Holme I, Aastveit AH, Kolar W, Steiner E. High apolipoprotein B, low apolipoprotein A-I, and improvement in the prediction of fatal myocardial infarction (AMORIS study): a prospective study. Lancet 2001; 358: 2026-33.

13 Salonen JT. Is there a continuing need for longitudinal epidemiologic research? The Kuopio Ischaemic Heart Disease Risk Factor Study. Ann Clin Res 1988; 20: 46-50.

14 Schwab U, Törrönen A, Toppinen L et al. Betaine supplementation decreases plasma homocysteine concentrations but does not affect body weight, body composition, or resting energy expenditure in human subjects. Am J Clin Nutr 2002; 76: 961-7.

15 Salonen JT, Nyyssönen K, Korpela H, Tuomilehto J, Seppänen $\mathrm{R}$, Salonen R. High stored iron levels are associated with excess risk of myocardial infarction in eastern Finnish men. Circulation 1992; 86: 803-11.

16 Salonen JT, Salonen R, Seppänen K, Rauramaa R, Tuomilehto J. HDL, HDL2, and HDL3 subfraction, and the risk of acute 
myocardial infarction: a prospective population study in eastern Finnish men. Circulation 1991; 84: 129-39.

17 Salonen JT, Seppänen K, Nyyssönen K et al. Intake of mercury from fish, lipid peroxidation and the risk of myocardial infarction and coronary, cardiovascular and any death in eastern Finnish men. Circulation 1995; 91: 645-55.

18 Vollset SE, Refsum H, Tverdal A et al. Plasma total homocysteine and cardiovascular mortality: the Hordaland Homocysteine Study. Am J Clin Nutr 2001; 74: 130-6.

19 Bostom AG, Silbershatz H, Rosenberg IH et al. Nonfasting plasma total homocysteine levels and all-cause and cardiovascular disease mortality in elderly Framingam men and women. Arch Intern Med 1999; 159: 1077-80.

20 Blacher J, Benetos A, Kirzin JM, Malejac A, Guize L, Safar ME. Relation of plasma total homocysteine to cardiovascular mortality in a French population. Am J Cardiol 2002; 90: 591-5.

21 Greenland S. Modelling and variable selection in epidemiologic analysis. Am J Public Health 1989; 79: 340-9.

22 Pekkanen J, Linn S, Heiss G et al. Ten-year mortality from cardiovascular disease in relation to cholesterol level among men with and without preexisting cardiovascular disease. $N$ Engl J Med 1990; 322: 1700-7.

23 Ernst E, Resch KL. Fibrinogen as a cardiovascular risk factor: a meta-analysis and review of the literature. Ann Intern Med 1993; 118: 956-63.

24 Roeters van Lennep JE, Westerveld HT, Erkelens DW, van der Wall EE. Risk factors for coronary heart disease: implications of gender. Cardiovasc Res 2002; 53: 538-49.
25 Chowienczyk PJ, Watts GF, Cockkroft JR, Ritte JM. Impaired endothelium-dependent vasodilatation of forearm resistance vessels in hypercholesterolemia. Lancet 1992; 340: 1430-2.

26 Leung WH, Lau CP, Wong CK. Beneficial effect of cholesterollowering therapy on coronary endothelium-dependent relaxation in hypercholesterolemic patients. Lancet 1993; 341: 1496-500.

27 Vaudo G, Marchesi S, Siepi D et al. Relevance of homocysteine on brachial flow-mediated vasodilatation and carotid and femoral intima-media thickness in patients with hypercholesterolemia. Am J Cardiol 2004; 93: 1413-6.

28 Mannucci PM. Recent progress in the pathophysiology of fibrinogen. Eur Heart J 1995; 16: 25-30.

29 Norio R. Diseases in Finland and Scandinavia. In: Rothscild HR, ed. Biocultural Aspects of Disease. Orlando, FL: Academic Press Inc., 1981; 358-415.

30 Brattström L, Wilcken DEL, Öhrvik J, Brudin L. Common methylenetetrahydrofolate reductase gene mutation leads to hyperhomocysteinemia but not to vascular disease. The result of a meta-analysis. Circulation 1998; 98: 2520-6.

31 Rady PL, Tyring SK, Hudnall SD et al. Methylenetetrahydrofolate reductase (MTHFR): the incidence of mutations C677T and A1298C in the Ashkenazi Jewish population. Am J Med Genet 1999; 86: 380-4.

Correspondence: Jyrki K. Virtanen, Research Institute of Public Health, University of Kuopio, PO Box 1627, 70211 Kuopio, Finland.

(fax: +358 17 162936; e-mail: jyrki.virtanen@uku.fi). 